\title{
EL MITO DE SÍSIFO Y SU SIGNIFICADO EN EL MUNDO ACTUAL. LOS MITOS EN LATINOAMÉRICA: BOLIVAR, JOSÉ MARTÍ Y FIDEL CASTRO. DESDÉN Y ANEMIA DE LOS MITOS NACIONALES: LAUTARO Y LA ARAUCANA*
} JAIME VALDIVIESO**

RESUMEN

La idea de esta ponencia es reflexionar so breel mito y sus variados significados ya sea en su sentido cotidiano de mentira, de fantasía, de obsesión por lo irreal cuando decimos de alguien que es un mitómano, un fabulador pero igualmente su relación con las representaciones y personajes más allá de la historia, tanto en la mitología griega como en la Biblia. Seguiremos en al gunos casos tanto los argumentos de M ircea Eliade, los arquetipos y la psicología profunda de Carl Jung, como las ideas de Thomas $M$ ann aplicadas a su propia experiencia de novelista, los variados ritos que en forma inconsciente revive el hombre diariamente, tal los ceremonial es que vienen de illo tempore, sentidos y conductas permanentes del hombre a través de la historia: celebraciones de año nuevo, los ritos de nacimiento y de muerte, y la propia existencia humana nunca singular e irrepetible sino afirmada en las pisadas de otras vidas que la preceden y le dan sentido y trascendencia.

Palabras daves: Fantasía, mitología griega, ritos, ceremoniales.

\section{ABSTRACT}

Theidea of this paper is to reflect on myth and its varied meanings. Whether it bein the everyday sense of a lie, a fantasy, an obsession for the unreal as when we say that someone is an exaggerator or myth-maker (mitómano), but also and equally in its relationship to representations and figures beyond history, as in Greek mythology or theBible. Wewill follow in some cases thearguments of M ircea Eliade and the archetypes of Carl Jung or the ideas of Thomas M ann applied to his own experience as novelist. We will also trace the varied rites that in unconscious form revivemen and women everyday, such as those ceremonies that come down illo tempore. We refer to meanings and permanent conducts of mankind throughout history such as celebrations of the new year, birth and death rites, and human existence itself, never singular and unrepeatable, but rather reaffirmed in the footsteps of other lives that come after and give meaning and transcendence.

Keywords: Fantasy, greek mythology, rites, ceremonies.

Recibido: 02.05.2003. Aprobado: 09.06.2003.

*Ponencia leída en la Escuela de Verano 2003 de la Universidad de Concepción.

**Crítico, ensayista, narrador y poeta. Ha publicado N unca el mismo río, El espejo y la palabra, Chile un mito y su ruptura, Cuerpo a cuerpo, Voces de alarma. 


\section{MITOS Y UTOPÍAS LATINOAM ERICANOS}

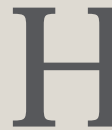

OY CASI NADIE desconoce que el descubrimiento deAmérica llevaba en sus entrañas la búsqueda y la posibilidad de las utopías.

Pero quizás muy pocos habrán pensado que la utopía conlleva, a la vez, al mito. La utopía: un mito al revés, proyección, anhelo, en lugar de nostal gia. Ambos son igualmente una necesidad y una conformidad: gracias a ellos escapamos a los terrores de la cotidianeidad, de la historia, y conocemos la estructura básica de los acontecimientos y de la vida humana: los arquetipos.

América Latina tenazmente continúa siendo fuente de mitos: su naturaleza y su pasado indígena fertilizan su imaginación y sus sueños: somos definitivamente el continente de la pasión y de los sentimientos, del tango, el bolero, los corridos; desde los poetas precolombinos, los modernistas hasta el realismo mágico y fantastico no hemos cesado de inventar futuros y de anhelar la vuelta de un pasado que fue más justo y humanizado. Continuamos habitando un espacio no enteramente desbastado con fuerte influencias de las culturas indígenas, donde la extensión y el tiempo se viven de otra manera. Tiempo mexicano llama Carlos Fuentes a uno de sus libros de ensayos sobre la idiosincrasia y el espíritu mexicanos. La cosmovisión indígena supone un tiempo circular, reversible, generador de vivencias rituales, mágicas y míticas que contaminan nuestra realidad y nuestra tradición expresada en el arte, especialmente en la literatura y la pintura.

Sin embargo, nos interesa aquí el significado del mito como verdad esencial, tal como lo concibe M ircea Eliade, distinto a la acepción de mito como mentira o fantasía en su sentido corriente ${ }^{1}$. Y también como una manera de concebir la realidad y la vida, de descubrirla y comprenderla en la vida y en la literatura.

Son también importantes en este aspecto las investigaciones del psicólogo Carl Jung. Para ambos el mito representa lo contrario de la historia, del acontecer lineal, irreversible, propio de la idea occidental del progreso. Lo mítico vendría a ser así una huida de la historia, pero una huida que es también regreso, vuelta a un pasado original, anterior al "logos", a la "racionalidad"; por lo tanto, una vía para alcanzar las estructuras profundas y permanentes de la existencia tal como la concibieron los griegos en sus grandes figuras míticas.

El hombre primitivo igual mente, el creador de las civilizaciones indígenasamericanas: la maya, la quechua, la mapuche, la guaraní, la azteca, aimara, etc., viven en el mito; todos los acontecimientos, aun los más nimios de la vida diaria como la pesca, la caza, las cosechas, las comidas, el nacimiento y

${ }^{1}$ Eliade, M ircea. M ith, Dreams and M ysteries, Trad. del francés por Philip M airer, Nueva York. Harper and Row, 1967, p. 79. 
la muerte, tienen un carácter reversible, y cada vez que los realiza repite una acción original, un rito, instaurado por sus antepasados en illo tempore. Y algunos hechos que afectan a la comunidad como las catástrofes: terremotos, huracanes, maremotos y otras formas devastadoras de la naturaleza, las asume como destino y fatalidad.

El hombre moderno, por otra parte, con fe y esperanza en el "progreso", y en el avanceincesante de la historia(concepto transparente en toda la obra de Hegel), necesita crear y recrear mitos; con ellos alimenta su imaginación y sus sueños; a través de ellos trasciende y combate la historia, la sequedad y el vacío del diario vivir. De aquí que transforme en mitos las ciudades, muchos acontecimientos de importancia colectiva, objetos materiales y culturales, ideas políticas y religiosas, los astros del deportey del cine, sus propios anhelos y fantasías. Todos ellos tienen algo en común como lo vio Eliade: "Porque es importante subrayar este hecho, analizando sobre todo la conducta del hombre moderno con respecto al tiempo, es como podemos penetrar los disfraces de su conducta mítica"2.

Pero no perdamos de vista la utopía. ¿No significa igualmente una salida dela historia, un arquetipo de comunidad, de país, de ideal? ¿No es acaso la utopía un mito invertido, una Edad de Oro, una Fuente de la Eterna Juventud, un El Dorado, una Ciudad de los Césares, proyectados hacia el futuro? Ambos: mito y utopía son, entonces, como el rostro de Jano: un ojo hacia adelante y el otro hacia atrás, uno al futuro y el otro al pasado. Y la literatura se alimenta de ellos, y a la vez alimenta los ideales eternos del hombre.

Octavio Paz, gran estudioso de los mitos y de la poesía, considera que poemas y mitos coinciden en transmutar el tiempo en una categoría temporal especial, un pasado siempre futuro y siempre dispuesto a ser presente, a "presentarse?.

Es, sobre todo, en la narrativa donde hallamos precisamente el imaginario de un mundo siempre mejor como alternativa de la sociedad impersonal, tecnificada y alienante en que vivimos. Y este mundo deseado y deseable se da especialmente en el mito, constante generador de ideal es y alimento de la memoria y de la identidad. En especial nos referimos a los mitos de fundación: fundación de ciudades más humanas y más justas, que recrean en el mundo de la palabra los narradores latinoamericanos, quienes en el más atolondrado vuelo de la fantasía jamás pierden de vista la contingencia. Carlos Fuentes al referirse a la necesidad de asumir el pasado, hablando de Bernal Díaz del Castillo, dice:

2Elkin, David, Freud, Jung and the anconscious, The New York Time Magazine, octubre. New York, 1970, p. 96.

${ }^{3}$ Eliade, M ircea, op. cit.

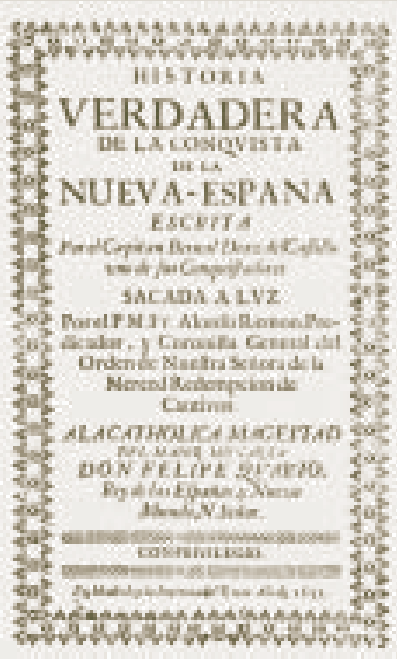




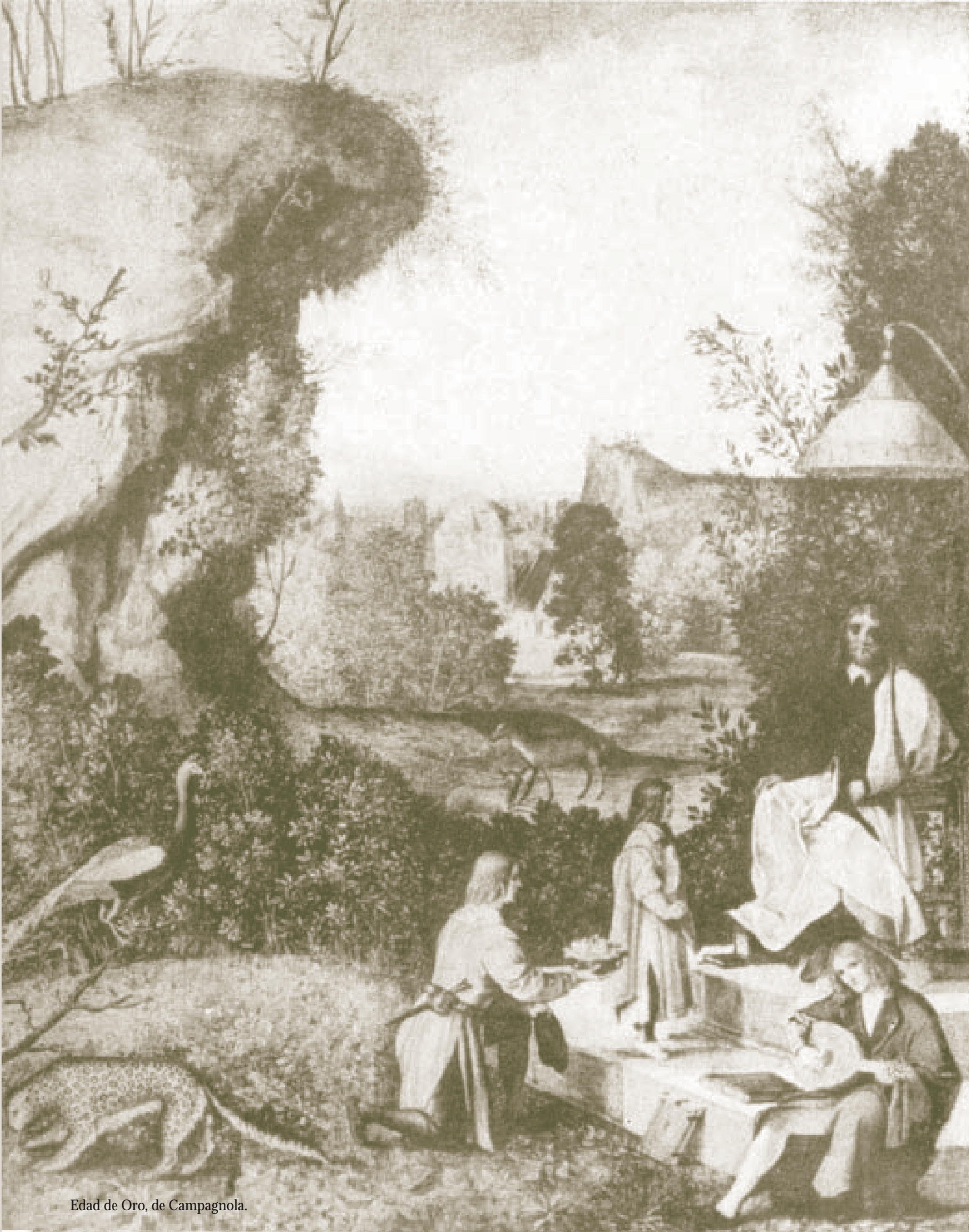


Esta melancólica admisión del pasado, este recurso de la memoria en el alba del valiente mundo nuevo que poderosamente se proyecta hacia el futuro, fundan el derecho de Bernal para estar presente en nuestra propia modernidad latinoamericana: También nosotros deberemos recordar claramente o no tendremos futuro ${ }^{4}$.

\section{El mito de Sísifo: Bolívar, José M artí y Fidel Castro}

Pero también existeel mito como absurdo, como trabajo despiadado y abrumador, tal el caso del mito de Sísifo entre otros tantos mitos griegos que actúan como prefiguraciones:

Sísifo era rey de Corinto. Un día por azar veuna gigantescaáguila, mayor y más espléndida que cualquier ave mortal llevando una joven hacia una isla cercana. Cuando el rey delos ríos Aesopus le comunicó quesu hija Aegina se la habían secuestrado y que sospechaba que era Zeus, le pidió quelo ayudara a buscarla. Sísifo le contó lo que había visto. Con lo cual se atrajo la tenaz furia deZeus que lo envió al infierno. Allí sele castigó para siemprea empujar una roca hasta la cima de una montaña y ver que antes de llegar rodaba hasta el lugar de la partida. Tampoco ayudó a Aesopus. El dios de los ríos fue a la isla pero Zeus lo destruyó con un rayo. El nombre de la isla se le llamó Aegina en honor de la joven y su hijo Aeacus fue el abuelo de Aquiles, a quien se lellamó algunas veces Aeacides, descendiente de Aeacus 5 .

Este mito podemos considerarlo como una metáfora dela vida contemporánea que abruma a los hombres, tal como a los antiguos héroes, a soportar duras pruebas, a estar dispuestos siempre como el castigo deSísifo a volver a empujar montaña arriba una pesada roca. Pero igualmentees una metáfora del coraje para decir la verdad. El anterior mito ha sido reinterpretado a la luz de la filosofía existencial y del absurdo bella y agudamente por el escritor y filósofo Albert Camus en su libro El mito de Sísifo. En nuestro continente sigue siendo vigente en figuras como Bolívar, José M artí y en el presente un héroe indiscutible, Fidel Castro, todos ellos vieron derrumbarse una y otra vez sus grandes aspiraciones y cada vez que estuvieron a punto de cumplir una meta, fuerzas adversas manejadas por países y grupos poderosos frustraron sus más nobles metas y debieron comenzar todo de nuevo.

No sólo los mitos de fundación, tal vez los más significativos en nuestra América atareada todavía en el proceso de fundar, aparecen con frecuencia en nuestra literatura (recuérdese el poema "Fundación mítica de Buenos Aires", de Jorge Luis Borges), sino igualmente se recrean en ella los mitos clási-

${ }^{4} \mathrm{H}$ amilton, Edith. M ithology, Signet Books, 1982.

${ }^{5}$ Fuentes, Carlos. La nueva novela, M éxico, Joaquín M ortiz, 1969, p. 16.

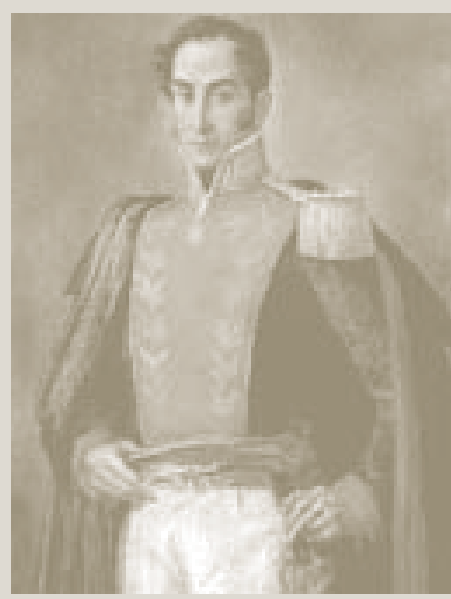

Simón Bolívar.

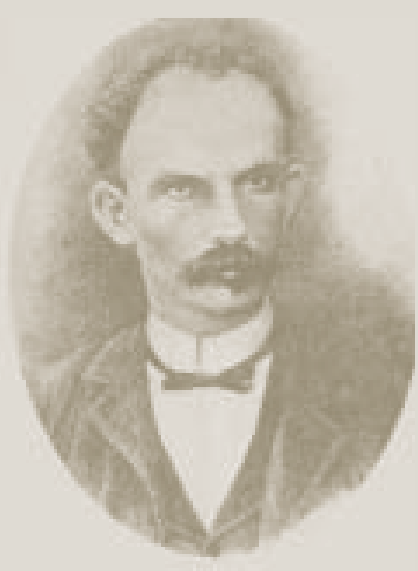

José M artí.

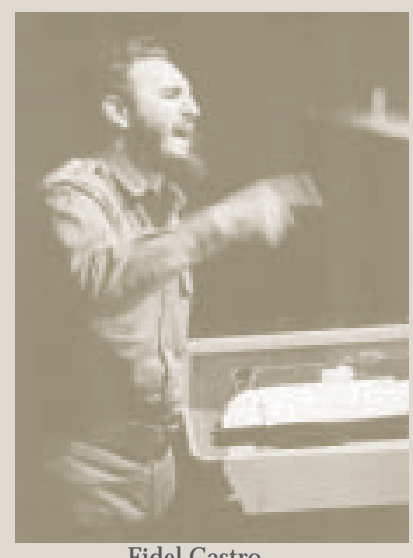

Fidel Castro. 


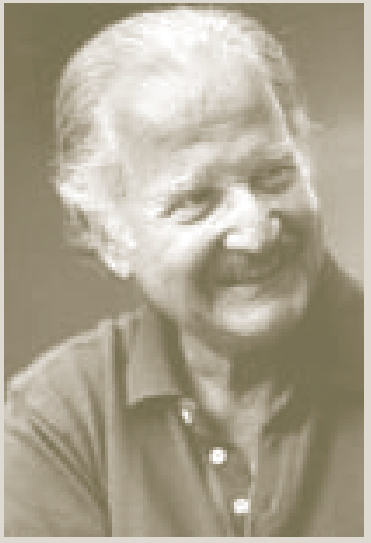

Carlos Fuentes

cos greco-latinos y bíblicos o de otras mitologías occidentales o indígenas. En Pedro Páramo, por ejemplo, aparecen numerosas figuras de los grandes mitos clásicos como lo vio Carlos Fuentes, tales como Telémaco, Orfeo y Edipo, Adán y Eva en la pareja incestuosa al fundar Comala. En Fernando del Paso la figura del destino absurdo de Palinuro en su novela Palinuro de M éxico.

De acuerdo a Jung no sólo existen los personajes arquetípicos (el héroe, el viejo sabio, etc.), sino temas (el amor, el odio, la fe), lugares (la caverna, el cruce de un río), y hasta estados de ánimo (tormentoso o sereno) ${ }^{6}$.

Estos arquetipos o mitos que no sólo se refieren a los personajes, sino a otros aspectos de una obra, son igual mente utilizados. La "persecución" aparece en El acoso y en Eloy de Carpentier y de Carlos Droguet, respectivamente; la batalla, en la escena delos estudiantes contra la policía en Paradiso, y la "caverna" en Rayuela, traspuesto como el subterráneo al que baja en ascensor O liveira a su regreso a Buenos Aires.

La mayor prueba de madurez en la novela latinoamericana reside en el hecho de que muchos escritores han descubierto el valor del mito como manera deelevar sus temas y personajes. Thomas $\mathrm{M}$ ann, quien siempretuvo una mirada serena y abisal para descifrar el al cance de la vida y el poder del arte, consideraba el empleo del mito como signo de madurez en el escritor: "Porque el mito es el fundamento de la vida, el esquema intemporal, la fórmula sagrada en la cual flota la vida cuando siguelas líneas del inconsciente. Por cierto, el día en que el escritor adquiere el hábito de considerar la vida como mítica y típica, su capacidad artística se expande notablemente, así como su poder perceptivo"7.

Cuando se habla de que Latinoamérica no ha tenido historia, que ha existido como "objeto", más que como "sujeto", se señala uno de sus rasgos sobresalientes: la a- historicidad y el carácter mítico de su acontecer.

M ito y utopía: dos caras de una misma medalla, dos formas de ruptura con el tiempo histórico, dos maneras de instrumentar la realidad y los sueños que nos permiten recuperar lo quehay de permanenteen el espíritu: los arquetipos desde los griegos y la Biblia hasta nuestros días.

\section{LoS MITOS DEGRAdAdOS: LAUTARO Y LA ARAu CANA}

En Chile, como consecuencias de nuestro desdén por el mundo indígena y la incapacidad y falta de voluntad para aceptar su legado espiritual y moral negando nuestro carácter mestizo, hemos desdeñado nuestra principal fuente de mitos: La Araucana de don Alonso de Ercilla y Zúñiga.

6jung, Carl.

7M ann, Thomas. "Freud and the Future". Essays, Nueva York. Alfred Knoph, 1957. 
Si bien las figuras de Lautaro, Caupolicán, Galvarino y otros de los entonces llamados araucanos fueron mencionados como héroes libertarios entre nuestros próceres como los hermanos Carrera, O'H iggins y don M ariano Egaña ${ }^{8}$ para motivar los deseos y propiciar la lucha por la independencia, pronto fueron olvidados por el afán eurocentrista de los primeros políticos y estadistas de la naciente república. Siguieron apareciendo como figuras epónimas distantes en el poema épico pero comenzaron a ser despreciados susherederos mapuches a los que poco a poco se les quitaron sus tierras y se consideró como raza vencida y humillada.

De acuerdo al antropólogo José Bengoa:

El heroico araucano pasó a ser el bárbaro y sanguinario indio del sur. Este estereotipo permitió que la sociedad chilena tuviera su conciencia tranquila respecto a la guerra de la frontera y viera ahora como héroes a los soldados que mataban a los antiguos héroes 9 .

Por eso los políticos que gobernaban el país a comienzos del siglo XX, en 1915, presentaron el Estado chileno como habitado mayoritariamente por la raza blanca cau cásica ${ }^{10}$ :

Los indígenas chilenos eran pues escasos, salvo en la región sur del valle longitudinal esto es, lo que después se llamó Araucanía. Por otra, las condiciones del clima muy favorables al desarrollo y la prosperidad de la raza blanca, hicieron innecesaria la importación de negros durante el período colonial... A estas circunstancias debeC hilesu admirablehomogeneidad bajo el aspecto de la raza. La blanca o caucásica predomina casi en absoluto, y sólo el antropólogo de profesión puede discernir los vestigios de la sangre aborigen, en las más bajas capas del pueblo ${ }^{11}$.

Las anteriores palabras dejan en claro cuál ha sido la posición del Estado en los últimos siglos y, por consiguiente, el espíritu con que han sido vistos los mapuches por la mayoría de los chilenos. Los quefueron héroes míticos en algún momento ahora son degradados y despreciados. Los únicos, por fortuna que han salido al paso de estas ideas sobre el indio actual son nuestros dos premios N obel y otros grandes poetas como Nicanor Parra, Gonzalo Rojas, Jorge Teillier y muy especial menteel gran poeta y narrador olvidado Luis Vulliamy. Neruda se refiere a Ercilla cómo "el inventor de Chile" y se

\footnotetext{
${ }^{8}$ Bengoa, José. Citado por Chihuailaf, Elicura, en "Está vivo el espíritu de la tierra en que hemos nacido". En Simpson 7, Revista de la Sociedad de Escritores de Chile, Volumen II, Segundo semestre. Santiago, 1992.

${ }^{9} \mathrm{Chihuailaf,} \mathrm{op.} \mathrm{cit.}$

${ }^{10}$ Neruda, Pablo, "Nosotros los indios". En John Skirius. El ensayo hispanoamericano del siglo XX, M éxico. F.C.E. Colección Tierra Firme, 1981.

${ }^{11}$ Chihuailaf, op. cit.
}

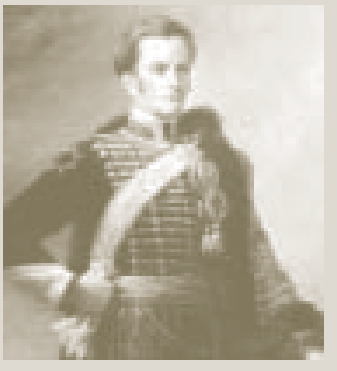

José M iguel Carrera.

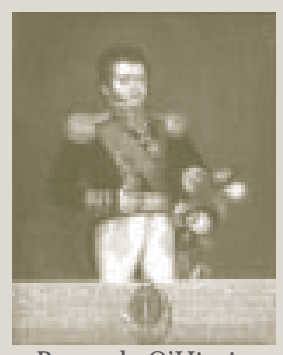

Bernardo O'Higgins. 
dio cuenta antes que nadie cómo el poema épico fundacional era un camino para los chilenos: “Compañero Alonso de Ercilla: La Araucana no sólo es un poema: es un camino". Y en su poema "Educación deun cacique" lerinde un bello, filial y acerado homenaje:

\section{Lautaro era una flecha acerada Elástico y azul fue nuestro padre. \\ Fue su primera edad sólo silencio.}

Fue así como se degradó nuestra principal fuente de mitos nacionales para los chilenos, pero sigue siendo fuente de energía y optimismo para los mapuches quetienen más de una incidencia entresu gente como nos diceel poeta Elicura Chihuailaf:

Ha cambiado la historia para nosotros, claro. Los "libros oficiales" dicen queson otros los que la hicieron y la siguen haciendo por nuestros pueblos. Los héroes de esta historia, en un mundo "civilizado" en el queya no debiera haberlos, son los invasores. Mas Caupolicán empalado, enfrentándolos, representa el suplicio de nuestro pasado que entra ardiendo en nuestros corazones. Lautaro es el futuro que vislumbramos, detrás de la cortina del misterio y del compromiso, y que saldrá como la luz de nuestros ojos ${ }^{12}$.

Ese camino queindicó Neruda desgraciadamenteno lo seguimos, lo perdimos y no lo hemos vuelto a tomar y con ello la fuentedelos mejores mitos nacionales identitarios.

Quisiera terminar esta ponencia con una reflexión un tanto aterradora. Pero si no es éste el sitio más adecuado para reflexionar sobre la crisis del momento en que vivimos, estaríamos bastante perdidos.

Creo que los mitos griegos es lo mejor que nos va quedando como estímulo y como utopías, ya que la desviación sufrida por el logos que viene a continuación, el culto a la lógica y a la teoría nos han llevado a la instrumentación tanto de las cosas como del hombretal como lo han visto los dos más importantes filósofos contemporáneos: Wittgenstein y Heidegger. Esteúltimo concluyecon un juicio aplastantecon respecto a lo queconocemos como el dominio de la técnica y la cosificación del hombre:

Al hombre "occidental" su peculiar historia lo ha transformado al cabo en el único ser inteligentequeentiende a la natural eza como un campo matemático de entes manipulables mediante instrumentos inventados por la inteligencia calculadora.

El cálculo y la manipulación de la naturaleza y de la sociedad en la edad del nihilismo ponen a todas las cosas y personas por igual a disposición de

${ }^{12}$ Chihuailaf, op. cit. 
los instrumentos racionales preparados para dominarlos.

REFERENCIAS

Chihuailaf, Elicura. 1992. "Está vivo el espíritu dela tierra en quehemosnacido". En Simpson 7, Revista de la Sociedad de Escritores de Chile. Volumen II, Segundo semestre. Santiago.

Eliade, M ircea. 1967. M ith, D reamsand M ysteries. Trad. del francés por Philip M airer, Nueva York. Harper and Row.

Elkin, David. 1970. "Freud, Jung and the anconscious", The N ew York Time M agazine, octubre. New York.

Fuentes, Carlos. 1969. La nueva novela. M éxico, Joaquín Mortiz, p. 16.

Hamilton, Edith. 1982. Mithology. Signet Books.

M ann, Thomas. 1957. Essays. "Freud and the Future". Nueva York. Alfred Knoph.

Neruda, Pablo. 1981. "Nosotroslosindios". En John Skirius. El ensayo hispanoamericano del siglo XX. M éxico. F.C.E. Colección Tierra Firme.

$\operatorname{lin}$ 
